\title{
Choroid Plexus Volume in Multiple Sclerosis vs Neuromyelitis Optica Spectrum Disorder
}

\author{
A Retrospective, Cross-sectional Analysis
}

Jannis Müller, MD, Tim Sinnecker, MD, Maria Janina Wendebourg, MD, Regina Schläger, MD, Jens Kuhle, MD, PhD, Sabine Schädelin, MSc, Pascal Benkert, PhD, Tobias Derfuss, MD, Philippe Cattin, PhD, Christoph Jud, PhD, Florian Spiess, MSc, Michael Amann, PhD, Therese Lincke, MD, Muhamed Barakovic, PhD, Alessandro Cagol, MD, Charidimos Tsagkas, MD, PhD, Katrin Parmar, MD, Anne-Katrin Pröbstel, MD, PhD, Sophia Reimann, Susanna Asseyer, MD, Ankelien Duchow, MD, Alexander Brandt, MD, Klemens Ruprecht, MD, Nouchine Hadjikhani, MD, PhD, Shoko Fukumoto, MD, Mitsuru Watanabe, MD, PhD, Katsuhisa Masaki, MD, Takuya Matsushita, MD, Noriko Isobe, MD, PhD, Jun-Ichi Kira, MD, PhD, Ludwig Kappos, MD, Jens Würfel, MD, PhD, Cristina Granziera, MD, PhD, Friedemann Paul, MD,* and Özgür Yaldizli, MD*

Neurol Neuroimmunol Neuroinflamm 2022;9:e1147. doi:10.1212/NXI.0000000000001147

\section{Abstract}

\section{Background and Objectives}

The choroid plexus has been shown to play a crucial role in CNS inflammation. Previous studies found larger choroid plexus in multiple sclerosis (MS) compared with healthy controls. However, it is not clear whether the choroid plexus is similarly involved in MS and in neuromyelitis optica spectrum disorder (NMOSD). Thus, the aim of this study was to compare the choroid plexus volume in MS and NMOSD.

\section{Methods}

In this retrospective, cross-sectional study, patients were included by convenience sampling from 4 international MS centers. The choroid plexus of the lateral ventricles was segmented fully automatically on T1-weighted MRI sequences using a deep learning algorithm (MultiDimensional Gated Recurrent Units). Uni- and multivariable linear models were applied to investigate associations between the choroid plexus volume, clinically meaningful disease characteristics, and MRI parameters.

\section{Results}

We studied 180 patients with MS and 98 patients with NMOSD. In total, 94 healthy individuals and 47 patients with migraine served as controls. The choroid plexus volume was larger in MS (median 1,690 $\mu \mathrm{L}$, interquartile range [IQR] $648 \mu \mathrm{L}$ ) than in NMOSD (median 1,403 $\mu \mathrm{L}, \mathrm{IQR}$ $510 \mu \mathrm{L}$ ), healthy individuals (median $1,533 \mu \mathrm{L}$, IQR $570 \mu \mathrm{L}$ ), and patients with migraine (median 1,404 $\mu \mathrm{L}$, IQR $524 \mu \mathrm{L}$; all $p<0.001$ ), whereas there was no difference between NMOSD, migraine, and healthy controls. This was also true when adjusted for age, sex, and the intracranial volume. In contrast to NMOSD, the choroid plexus volume in MS was associated

\footnotetext{
*These authors contributed equally to this work (co-senior authors).

From the Neurology Clinic and Policlinic (J.M., T.S., M.J.W., R.S., J.K., S.S., P.B., T.D., M.B., A.C., C.T., K.P., A.-K.P., S.R., L.K., C.G., O.Y.), Departments of Head, Spine and Neuromedicine, MS Center and Research Center for Clinical Neuroimmunology and Neuroscience Basel (RC2NB), Clinical Research and Biomedical Engineering, University Hospital Basel and University of Basel; Translational Imaging in Neurology (ThINk) Basel (J.M., S.S., M.B., A.C., C.T., K.P., C.G., O.Y.), Department of Biomedical Engineering, University Hospital Basel and University of Basel, Switzerland; Department of Biomedical Engineering (P.C., C.J., F.S., J.W., C.G.), University of Basel, Allschwil, Switzerland; Medical Imaging Analysis Center AG (M.A., J.W.); Section of Neuroradiology (T.L.), Clinic for Radiology \& Nuclear Medicine, University Hospital Basel and University of Basel, Switzerland; Reha Rheinfelden (K.P.), Rheinfelden, Switzerland; NeuroCure Clinical Research Center and Experimental and Clinical Research Center (S.A., A.D., A.B., J.W., F.P.), Max Delbrueck Center for Molecular Medicine and Charité-Universitätsmedizin Berlin, Germany; Department of Neurology (A.B.), University of California, Irvine; Department of Neurology (K.R.), Charité-Universitätsmedizin Berlin, corporate member of Freie Universität Berlin and Humboldt-Universität zu Berlin, Germany; Martinos Center for Biomedical Imaging (N.H.), Massachusetts General Hospital and Harvard Medical School, Boston; Gillberg Neuropsychiatry Center (N.H.), Sahlgrenska Academy, University of Gothenburg, Sweden; Department of Neurology (S.F., M.W., K.M., T.M., N.I., J.-I.K.), Neurological Institute, Graduate School of Medical Sciences, Kyushu University, Fukuoka, Japan; Department of Neurology (J.-I.K.), Brain and Nerve Center, Fukuoka Central Hospital, International University of Health and Welfare, Fukuoka; and Translational Neuroscience Center (J.-I.K.), Graduate School of Medicine, and School of Pharmacy at Fukuoka, International University of Health and Welfare, Okawa, Japan.
} 


\section{Glossary}

DMT = disease-modifying treatment; EDSS = Expanded Disability Status Scale; ET = echo time; FLAIR = fluid-attenuated inversion recovery; FOV = field of view; HCs = healthy control; Ig = immunoglobulin; IQR = interquartile range; IT = inversion time; n.a. = not applicable/available; NMOSD = neuromyelitis optica spectrum disorder; MOG = myelin oligodendrocyte glycoprotein; MPRAGE = magnetization-prepared rapid gradient echo; $\mathbf{M S}=$ multiple sclerosis; RRMS = relapsing-remitting multiple sclerosis; $\mathbf{R O C}=$ receiver operating characteristic; RT = repetition time; SMSC = Swiss Multiple Sclerosis Cohort; SPMS = secondary progressive multiple sclerosis; TIV = total intracranial volume; T1w $=\mathrm{T} 1$ weighted; T2 $\mathbf{w}=$ T2 weighted; $3 \mathbf{T}=3$ Tesla.

with the number of T2-weighted lesions in a linear model adjusted for age, sex, total intracranial volume, disease duration, relapses in the year before MRI, disease course, Expanded Disability Status Scale score, disease-modifying treatment, and treatment duration (beta 4.4 ; 95\% CI $0.78-8.1 ; p=0.018$ ).

\section{Discussion}

This study supports an involvement of the choroid plexus in MS in contrast to NMOSD and provides clues to better understand the respective pathogenesis.

The choroid plexus is constituted by cuboid epithelial cells ensheathing fenestrated blood vessels and a connective stroma. ${ }^{1}$ It is located inside the brain ventricles and produces CSF in the vertebrate brain. ${ }^{2}$ The choroid plexus is essential for the development, maintenance, and normal function of the brain ${ }^{1,2}$ and serves as a port of entry for immune cells to the $\mathrm{CNS}^{2,3}$ It is both a target and modulator of inflammation. ${ }^{4}$

Histopathologic studies in multiple sclerosis (MS) showed inflammation and enlargement of the choroid plexus due to edema with high concentrations of $\mathrm{T}$ lymphocytes, dendritic cells, and activated macrophages. ${ }^{4,5}$ These studies also found increased concentrations of vascular cell adhesion protein 1 staining indicating active recruitment of peripheral inflammatory cells. ${ }^{2,-8}$ In a postmortem study, the immune cell pattern in the choroid plexus observed in MS was similar to that seen in acute viral encephalitis with activation of immune cells and enlargement of choroid plexus stroma cells. ${ }^{4}$

Recently, a 3 tesla (3T) MRI and PET study confirmed larger choroid plexus and higher fluorine 18 fluorodeoxyglucose uptake in the choroid plexus of 97 patients with MS compared with 44 healthy controls (HCs) in vivo indicating inflammation within the choroid plexus of patients with MS. ${ }^{9}$ The same research group recently found enlarged choroid plexus in individuals with a radiologically isolated syndrome (presymptomatic stage of the disease) compared with HCs, supporting the hypothesis of enlargement of the choroid plexus due to MS-related inflammation. ${ }^{10}$

Neuromyelitis optica spectrum disorder (NMOSD) has a different pathophysiology than MS. ${ }^{11}$ In contrast to MS, NMOSD is an antibody-mediated inflammation. ${ }^{11}$ The antigen is aquaporin-4, a water channel molecule that is abundant on the astrocyte end feet in the CNS. ${ }^{11}$ The antigen-antibody reaction triggers astrocyte injury through complement-dependent cytotoxicity. So, the breakdown of the blood-brain barrier in NMOSD is less dependent on the migration and infiltration of lymphocytes into the choroid plexus as seen in MS but on antibodies against aquaporin4. ${ }^{12-14}$ Thus, we hypothesized that the choroid plexus is larger in MS than NMOSD, and if this is true, the choroid plexus volume measured using MRI might be helpful to distinguish both conditions.

Recently, a study that compared the choroid plexus size between MS and NMOSD did not find significant differencens between the 2 diseases. ${ }^{15}$ However, that study included only a small number of patients (51 patients with MS and 32 patients with NMOSD), and used only linear measures on axial and coronal MRI slices to calculate the choroid plexus volume. Therefore, we aimed to investigate the choroid plexus volume in MS vs NMOSD in a larger study population and using high-resolution 3D MRI data in a multicenter setting.

\section{Methods}

\section{Study Design and Participants}

This study was designed as a retrospective, cross-sectional MRI study to compare the choroid plexus volume between patients with MS and NMOSD in vivo. We included healthy individuals and patients with migraine as controls. Migraine was chosen as an example of a nonautoimmune inflammatory CNS disease.

Our null hypothesis was that there is no difference in the choroid plexus volume between MS and NMOSD compared with migraine and HCs. We planned a priori to investigate the associations between the choroid plexus volume and disease characteristics in MS and NMOSD. 
MRI and clinical data derived from 4 MS centers including the University Hospital of Basel (Switzerland; Swiss MS cohort study), ${ }^{16}$ Kyushu University Hospital in Fukuoka (Japan), Charité - Universitätsmedizin Berlin (Germany), and the Centre Hospitalier Universitaire Vaudois, Lausanne (Switzerland). The inclusion criteria for this study were the diagnosis of MS or NMOSD and a full 3T MRI data set consisting of a T1-weighted magnetization-prepared rapid gradient echo (MPRAGE) image and a fluid-attenuated inversion recovery (FLAIR) sequence. Patients with MS had to fulfill the McDonald criteria 2010, ${ }^{17}$ patients with NMOSD the 2015 International Panel for NMO Diagnosis criteria, ${ }^{18}$ and patients with migraine the diagnostic criteria of the International Headache Society. ${ }^{19} \mathrm{HCs}$ were included from Basel, Lausanne, and Fukuoka. The patients with migraine derived from Basel and Lausanne. We excluded individuals with any other comorbidity of the CNS (except of migraine). We also checked all MRIs for incidental findings associated with the choroid plexus (such as plexus papilloma or ependymoma), which have not been detected in any of the study participants.

\section{Clinical Characteristics}

The MS disease course (relapsing-remitting [RR] MS or secondary progressive $[\mathrm{SP}] \mathrm{MS}$ ) was defined according to the Lublin criteria. ${ }^{20}$ Disease duration in MS and NMOSD was defined as time between first symptoms of the disease and the MRI time point. The disability status was measured using the Expanded Disability Status Scale (EDSS). ${ }^{21}$ Relapses were defined as new or recurring neurologic deficits or symptoms associated with MS or NMOSD that lasted for at least 24 hours in the absence of fever or an infection and could not be better explained by any other comorbidity. ${ }^{22}$ Serum antibody diagnostic testing was conducted using state-of-the-art cell-based assays. ${ }^{23,24}$ To include the MS disease-modifying treatment (DMT) as covariate into the linear model, we grouped the treatments into 3 efficacy categories: 1 = first generation injectables (interferon-beta and glatiramer acetate); 2 = orals (dimethyl fumarate, teriflunomide, and fingolimod); 3 = IV (natalizumab, rituximab, ocrelizumab, mitoxantrone, and stem cell therapy).

\section{MRI Acquisition and Analysis}

MRI scanner type and acquisition parameters are provided in Table 1. T2-weighted (T2w) white matter lesions were segmented fully automatically on FLAIR images using a deep learning algorithm (Multi-Dimensional Gated Recurrent Units). ${ }^{25}$ We used the same algorithm to segment the lateral ventricle choroid plexus on 3D T1-weighted MPRAGE sequences (Figure 1). The algorithm is available on GitHub (github.com/zubata88/mdgru). The deep learning algorithm was trained with 125 manual lateral ventricle choroid plexus segmentations: 42 in patients with MS, 38 in patients with migraine, and 45 in healthy controls. These choroid plexus maps were quality checked by a board-certified neuroradiologist and served as ground truth for the machine learning algorithm. To control for the head size, we adjusted the statistical models for total intracranial volume (TIV) and in a sensitivity analysis for the lateral ventricle volume. TIV and lateral ventricle volume were measured using FreeSurfer (surfer.nmr.mgh.harvard.edu/) on white matter lesion-filled T1-weighted MPRAGE sequences. Similar to a previously published study, ${ }^{9}$ we reported the choroid plexus volume also relative to the TIV.

To investigate the association between choroid plexus volume and distance of $\mathrm{T} 2 \mathrm{w}$ white matter lesions to the lateral ventricle wall, we parcellated the white matter in concentric 1-voxel thick white matter bands by repeatedly dilating the lateral ventricle mask by 1 voxel $\left(1 \times 1 \times 1 \mathrm{~mm}^{3}\right)$ using the DilM option in Functional MRI Brain Software Library 6.0.1 (FSL) ${ }^{26}$ on T1w MPRAGE (Figure 1B). To minimize partial volume effects, we eliminated the first band from the analysis. We assessed the T2w lesion number and volume in each periventricular white matter band separately. All outputs were reviewed by experienced raters and corrected manually, blinded to the clinical data using 3D slicer (slicer.org, Version 4.6.2). In total, 151/419 (36\%) of automated choroid plexus segmentations needed minor corrections (only a few voxels for most of the scans).

\section{Statistical Analysis}

We used data from a recent study ${ }^{15}$ for an a priori sample size calculation ( $t$ test for independent samples). That study ${ }^{15}$ found a mean choroid plexus diameter of $2.09+/-0.49 \mathrm{~mm}$ on coronal plane in MS vs $1.89+/-0.48 \mathrm{~mm}$ in NMOSD. We calculated a minimum of 47 patients that would be needed in each group to detect a significant difference between the groups with a type I error rate of $5 \%$ and a power of $80 \%$. Normality of the variables was evaluated visually using Q-Q plots. Normally distributed variables are displayed as mean \pm $1 \mathrm{SD}$. Skewed variables are reported as median and interquartile range (IQR). We used the Mann-Whitney $U$ test (ordinal and continuous variables) and the $\chi^{2}$ test (proportions) to compare baseline characteristics between the groups. Associations were analyzed using uni- and multivariable linear models adjusted for clinically meaningful covariates. Estimates (beta) are presented together with $95 \%$ CIs and $p$ values. We performed 3 sensitivity analyses, which were planned a priori: (1) we compared the choroid plexus volume between MS and NMOSD including the infratentorial parts of the choroid plexus in a subgroup 20 patients; (2) we additionally adjusted our statistical models for different MRI scanner types and study centers; and (3) we included the lateral ventricle volumes as covariate into the multivariable linear model.

We also performed a post hoc analysis: As we found an association between $\mathrm{T} 2 \mathrm{w}$ lesion burden and the choroid plexus volume in MS, we were interested whether the observed difference in the choroid plexus volume between MS and NMOSD and between MS and HCs is also detectable in the subgroup of patients with a low T2w lesion burden. We defined low T2w lesion burden as $<13$ lesions, which corresponds to the patients with the $25 \%$ lowest T2 lesion number of the MS group.

Receiver operating characteristic (ROC) curves were used to assess the sensitivity, specificity, and accuracy of the choroid 
Table 1 MRI Acquisition Parameters

\begin{tabular}{|c|c|c|c|c|c|c|c|c|c|}
\hline Group & $\mathbf{N}$ & Location & Scanner type & Field strength & Voxel size $(\mu \mathrm{L})$ & $\mathrm{RT}$ (ms) & IT (ms) & ET (ms) & FOV $(\mathrm{mm})$ \\
\hline MS & 97 & University Hospital Basel & Siemens Skyra & ЗТ & $1 \times 1 \times 1$ & 2,300 & 900 & 2 & $256 \times 240$ \\
\hline MS & 83 & Kyushu University, Fukuoka & Philips Achieva & 3T & $1 \times 1 \times 1$ & 7.5 & n.a. & 3.5 & $240 \times 240$ \\
\hline NMOSD & 6 & University Hospital Basel & Siemens Skyra & 3T & $1 \times 1 \times 1$ & 2,300 & 900 & 2 & $256 \times 240$ \\
\hline NMOSD & 49 & Charité Hospital Berlin & Siemens Trio & 3т & $1 \times 1 \times 1$ & 1900 & 900 & 3.03 & $256 \times 256$ \\
\hline NMOSD & 43 & Kyushu University, Fukuoka & Philips Achieva & 3T & $1 \times 1 \times 1$ & 7.5 & n.a. & 3.5 & $240 \times 240$ \\
\hline HCs & 20 & University Hospital Basel & Siemens Skyra FIT & 3Т & $1 \times 1 \times 1$ & 2,300 & 900 & 2 & $256 \times 240$ \\
\hline HCs & 20 & University Hospital Basel & Prisma & 3т & $1 \times 1 \times 1$ & 2000 & 1,100 & 2.1 & $256 \times 256$ \\
\hline HCs & 15 & University Hospital Lausanne & Siemens Trio & $3 T$ & $1 \times 1 \times 1$ & 2,400 & 900 & 3 & $256 \times 240$ \\
\hline HCs & 16 & University Hospital Basel & Siemens Skyra & $3 T$ & $1 \times 1 \times 1$ & 2,300 & 900 & 3 & $256 \times 240$ \\
\hline HCs & 23 & Kyushu University, Fukuoka & Philips Achieva & 3Т & $1 \times 1 \times 1$ & 7.5 & n.a. & 3.5 & $240 \times 240$ \\
\hline Migraine & 19 & University Hospital Basel & Siemens Skyra & зт & $1 \times 1 \times 1$ & 2,300 & 900 & 2 & $256 \times 240$ \\
\hline Migraine & 28 & University Hospital Lausanne & Siemens Trio & 3Т & $1 \times 1 \times 1$ & 2,400 & 900 & 3 & $256 \times 240$ \\
\hline
\end{tabular}

Abbreviations: $\mathrm{ET}=$ echo time; FOV = field of view; $\mathrm{HCS}=$ healthy controls; IT = inversion time; $\mathrm{RT}=$ repetition time; $3 \mathrm{~T}$ = 3 Tesla; MS = multiple sclerosis; $\mathrm{N}=$ number of study participatns; n.a. = not applicable/available; NMOSD = neuromyelitis optica spectrum disorder.

plexus size to discriminate MS from NMOSD in comparison to the number of T2-weighted lesions. To obtain estimates for the association between the choroid plexus volume and the disease course (MS vs NMOSD), we performed a logistic regression model with the disease group as dependent variable and both the choroid plexus volume and clinically meaningful variables as covariates (eTable 3, links.lww.com/NXI/A701).

All statistical tests were 2 tailed. We used the conventional significance threshold of $p<0.05$. Statistical analyses were performed using IBM SPSS Statistics (version 25; IBM, Armonk, NY).

\section{Ethics Approval}

This study was approved by the ethics committee North-West and Central Switzerland (reference 2020-01364).

\section{Data Availability}

Clinical and MRI data are accessible at the Department of Biomedical Engineering and the Department of Clinical
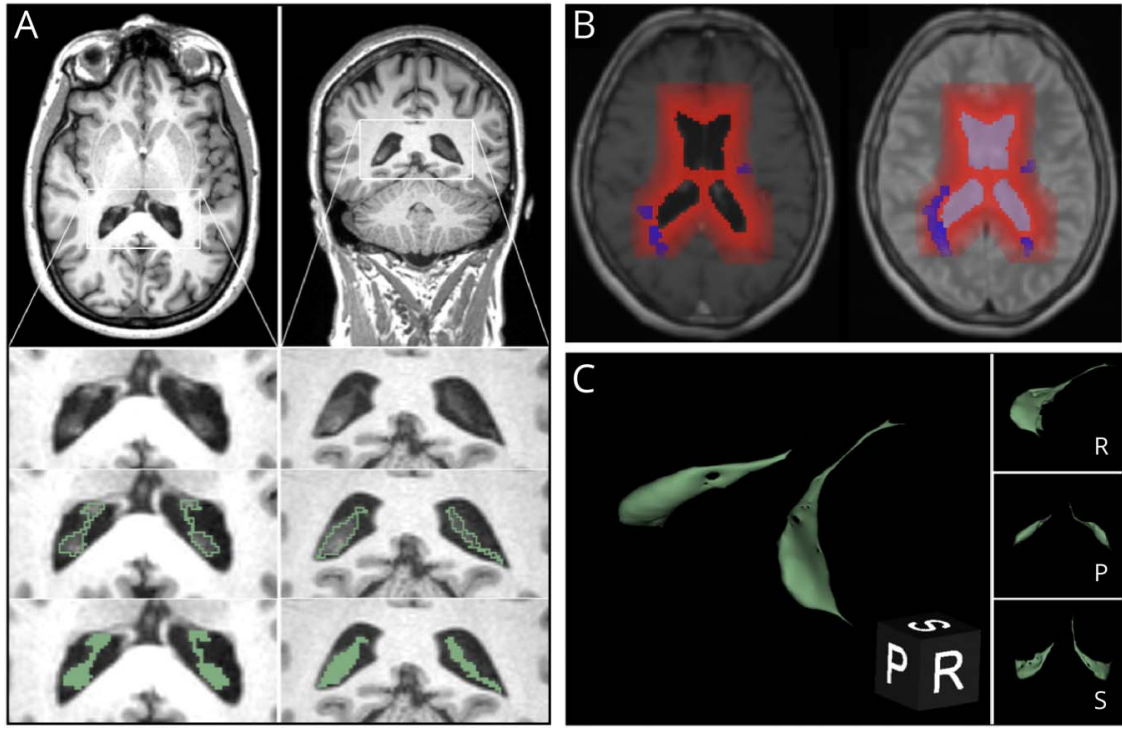

(A) Automated segmentation (green) of the brain lateral ventricle choroid plexus in a multiple sclerosis patient using multi-dimensional gated recurrent units. ${ }^{25}$ (B) Parcellation of the white matter into periventricular bands. To investigate the association between choroid plexus volume and distance between MS and lateral ventricle wall, we parcellated the white matter into periventricular bands extending from the lateral ventricle to the cortex. As a precaution against periventricular CSF / white matter partial volume effects, we excluded data from the first periventricular band. The white matter band masks were applied on co-registered T1- and T2w lesion masks to calculate the volume of lesions in each periventricular band. Lesions are marked in dark blue and the white matter bands in red. (C) 3Dmodel of the choroid plexus, based on segmentation of $(\mathrm{A})$. $\mathrm{P}=$ posterior; $\mathrm{R}=$ right; $\mathrm{S}=$ superior 
Table 2 Demographics, Clinical Characteristics, and MRI Variables of the Study Participants

\begin{tabular}{|c|c|c|c|}
\hline & MS & NMOSD & $p$ Value \\
\hline $\mathbf{N}$ & 180 & 98 & \\
\hline \multicolumn{4}{|l|}{ Centers, $\mathbf{n}$} \\
\hline Basel (Switzerland) & 97 & 6 & \\
\hline Lausanne (Switzerland) & n.a. & n.a. & \\
\hline Berlin (Germany) & n.a. & 49 & \\
\hline Fukuoka (Japan) & 83 & 43 & \\
\hline \multicolumn{4}{|l|}{ Demographics } \\
\hline Age, y, median (IQR) & $46.6(15.3)$ & $54.5(18.5)$ & $<0.001 *$ \\
\hline Women, n (\%) & $126(70 \%)$ & $86(88 \%)$ & $0.001 *$ \\
\hline \multicolumn{4}{|l|}{ Clinical characteristics } \\
\hline RRMS, n (\%) & $135(75 \%)$ & n.a. & \\
\hline SPMS, n (\%) & $45(25 \%)$ & n.a. & \\
\hline Disease duration, $y$, median (IQR) & $14.8(13.6)$ & $7.8(9.6)$ & $<0.001$ * \\
\hline EDSS score, median (IQR) & $2.5(3.5)$ & $3.5(2.8)$ & 0.062 \\
\hline Patients with relapse within the 12 months before MRI, number (\%) & $27(15 \%)$ & $21(21 \%)$ & 0.083 \\
\hline Time since last relapse, $y$, median (IQR) & $4.5(6.9)$ & $3.3(4.8)$ & 0.011 * \\
\hline Patients on DMT, n (\%) & $153(85 \%)^{a}$ & $89(91 \%)^{b}$ & $0.001 *$ \\
\hline Time on present DMT, y, median (IQR) & $2.9(3.9)$ & $4.4(8.1)$ & $0.005^{*}$ \\
\hline \multicolumn{4}{|l|}{ Laboratory } \\
\hline Patients with anti-aquaporin-4 antibodies, $\mathrm{n}(\%)$ & n.a. & $71 / 86(83 \%)$ & \\
\hline Patients with anti-MOG antibodies, $\mathrm{n}(\%)$ & n.a. & $11 / 86(13 \%)$ & \\
\hline \multicolumn{4}{|l|}{ Brain MRI } \\
\hline Patients with gadolinium-enhancing lesions, n (\%) & $2(<1 \%)$ & 0 & \\
\hline T2w lesion number, median (IQR) & $21(27)$ & $11(16)$ & $<0.001$ * \\
\hline T2w lesion volume, mL, median (IQR) & $11.8(21.7)$ & $1.6(6.4)$ & $<0.001$ * \\
\hline Total intracranial volume, $\mathrm{mL}$, mean $\pm \mathrm{SD}$ & $1,433 \pm 181$ & $1,439 \pm 178$ & 0.706 \\
\hline
\end{tabular}

Abbreviations: DMT = disease-modifying treatment; EDSS = Expanded Disability Status Scale; IQR = interquartile range; MOG = myelin oligodendrocyte glycoprotein; MS = multiple sclerosis; $\mathrm{n}$ = number; $\mathrm{n} . \mathrm{a}$. = not applicable/available; NMOSD = neuromyelitis optica spectrum disorder; $\mathrm{SPMS}=$ secondary progressive multiple sclerosis; SD = SD; $T 2 \mathrm{w}=\mathrm{T} 2$ weighted.

Statistically significant differences between MS and NMOSD are marked with an asterisk.

a Interferon-beta or glatiramer acetate: $\mathrm{n}=30$; dimethyl fumarate, fingolimod, or teriflunomide: $n=85$; natalizumab, rituximab, ocrelizumab, or stem cell therapy: $n=34$; azathioprine: $n=1$; corticosteroid pulse therapy every 3 months: $n=1$; intrathecal triamcinolone ever 3 months: $n=1$; mitoxantrone: $n=1$. ${ }^{b}$ Azathioprine, mycophenolate mofetil, methotrexate, or tacrolimus: $n=42$ (some of these patients $[n=12$ patients with azathioprine and $n=8$ patients with tacrolimus] had add-on oral prednisolone therapy with a dose ranging from 5-20 mg/d), monotherapy oral prednisolone: $n=21$, rituximab: $n=26$.

${ }^{c} n=49 / 180$ patients with MS (27.2\%) had a relapse within 24 months before MRI (44 of them had RRMS).

Research (Clinical Trial Unit) of the University of Basel via the corresponding author.

\section{Results}

\section{Demographics and Clinical Characteristics}

We included 180 patients with MS and 98 patients with NMOSD from 3 different MS centers (Table 2). In total, 47 patients with migraine (19 from Basel and 28 from Lausanne) and 94 healthy individuals ( 56 from Basel, 15 from Lausanne, and 23 from Fukuoka) served as controls.

The patients with NMOSD in our study were older than the patients with MS $(p<0.001)$, whereas there was no significant age or sex difference between MS, migraine, and healthy individuals (MS: median age 46.6 years, IQR 15.3 years, $70 \%$ female; migraine: median age 42.2 years, IQR 18.3 years, $72 \%$ female; HCs: median age 46.1 years, IQR 22.3 years, $64 \%$ female). 
Typical for the difference between patients with MS and NMOSD, ${ }^{27}$ the proportion of women was higher in NMOSD than in MS $(p=0.001)$. Moreover, disease duration was longer in patients with MS than patients with NMOSD $(p<$ $0.001)$, whereas the median EDSS score was similar between the 2 groups.

In this study, patients with NMOSD had a shorter time between last relapse and MRI than the patients with MS (median time 3.3 vs 4.5 years; $p=0.01$ ). Moreover, only $21 \%$ and $15 \%$ of the NMOSD and MS groups, respectively, had a relapse in the year before the MRI. In total, 44/135 patients with RRMS (33\%) had a relapse in the 24 months before the MRI.

Typical for NMOSD, ${ }^{27}$ the patients with NMOSD in this study had significantly fewer T2-weighted lesions than patients with MS. There was no difference between MS and NMOSD regarding the TIV.

The antibody status was available for $86 / 98$ (88\%) patients with NMOSD: 71 were positive for aquaporin- 4 antibody and 11 patients for anti-myelin oligodendrocyte glycoprotein; 4 patients were negative for both antibodies. None of the patients were positive for both anti-aquaporin-4 antibody and anti-MOG antibody. In 12/98 (12\%) patients with NMOSD, the antibody status was not available, and the diagnosis was made based on clinical criteria only. ${ }^{18}$ Most of the patients with MS (153/180; 85\%) were treated with a DMT at time of the MRI. Details are given in the legend of Table 2.

In total, 23/47 patients with migraine (49\%) had a migraine with aura. Two patients with MS also had a migraine (both without aura). Some patients with migraine had unspecific T2w white matter hyperintensities. Those were not segmented as lesions as they are believed to have no clinical significance. $^{28}$

\section{Association Between Age, Sex, Total Intracranial Volume, and the Choroid Plexus Volume in Healthy Individuals and Patients With Migraine}

In HCs, there was no association between the choroid plexus volume and age or sex when adjusted for TIV. The same was true for the migraine group. Details are given in the supplementary material (eTable 1, links.lww.com/NXI/A701).

\section{Choroid Plexus Volume in MS vs NMOSD Compared With the Control Groups}

The choroid plexus was larger in MS than NMOSD (median $1,690 \mu \mathrm{L}, \mathrm{IQR} 648 \mu \mathrm{L}$ vs $1,403 \mu \mathrm{L}, \mathrm{IQR} 510 \mu \mathrm{L}$; beta 121.8 ; 95\% CI:81.8-161.8; $p<0.001$ ) (Figure 2). Choroid plexus volume, expressed as a ratio of TIV, was on average $20.5 \%$ larger in MS than NMOSD $\left(12.13 \times 10^{-4} \pm 2.75 \times 10^{-4}\right.$ vs $\left.10.07 \times 10^{-4} \pm 2.32 \times 10^{-4}\right)$. When adjusting for age, sex, TIV, disease duration, relapses in the previous year, EDSS score, and $\mathrm{T} 2 \mathrm{w}$ lesion number, the choroid plexus was still larger in
MS than NMOSD (beta 92.8; 95\% CI: 55.5-130.2; $p<0.001$; eTable 2, links.lww.com/NXI/A701).

The choroid plexus was also larger in MS than HCs (beta 292; 95\% CI: $192-393 ; p<0.001)$. Expressed as a ratio of TIV, the mean choroid plexus volume was $21.4 \%$ higher in MS than HCs $\left(12.13 \times 10^{-4} \pm 2.75 \times 10^{-4}\right.$ vs $9.99 \times 10^{-4} \pm 2.51 \times$ $\left.10^{-4}\right)$. Similarly, the choroid plexus volume was larger in patients with MS than in patients with migraine (median 1,404 $\mu \mathrm{L}, \mathrm{IQR} 524 \mu \mathrm{L}$; beta 153; 95\% CI: 83-223; $p<0.001$ ). Relative to TIV, the mean choroid plexus volume was $23 \%$ higher in MS than migraine $\left(12.13 \times 10^{-4} \pm 2.75 \times 10^{-4}\right.$ vs $\left.9.86 \times 10^{-4} \pm 2.63 \times 10^{-4}\right)$. In contrast, there was no difference in the choroid plexus volume between NMOSD, migraine, and healthy individuals.

\section{Choroid Plexus Volume and Disease Characteristics in MS}

In MS, there was no association between the choroid plexus volume and disease duration, disease course, or the EDSS score at time of the MRI when adjusted for age, sex, and TIV. The choroid plexus volume was similar in patients with and without a relapse within the 12 months before the MRI. There was an association between the time to last relapse and the choroid plexus volume in the subgroup of 135 patients with RRMS (beta 1.1 ; 95\% CI: 0.1-2.1; $p=0.03$; adjusted for age, sex, and TIV): RRMS patients with longer time since last relapse had marginally higher choroid plexus volumes. However, when adjusting for T2w lesion number, the association between the time since last relapse and choroid plexus volume lost statistical significance. This indicated a strong association between the choroid plexus volume and the T2w lesion burden, and indeed, we found an association between the choroid plexus volume and the number of T2w white matter lesions in the MS group: on average, every $\mathrm{T} 2 \mathrm{w}$ lesion in MS increased the choroid plexus volume statistically by $4.4 \mu \mathrm{L}$ (beta 4.4 ; 95\% CI: $0.78-8.1 ; p=0.018)$, adjusted for age, sex, TIV, relapse in the previous year, disease course, EDSS score, DMT category, and DMT duration (Table 3). The choroid plexus volume was also higher in the subgroup of patients with RRMS with low T2w lesion number (for definition, see the Methods section) compared with HCs, adjusted for age, sex, and TIV (beta 49; 95\% CI: $12-85 ; p=0.009$ ). There was no association between the volume of $\mathrm{T} 2 \mathrm{w}$ lesions and the choroid plexus volume. We also did not find any association between the distance of the $\mathrm{T} 2 \mathrm{w}$ lesions to the lateral ventricle and the choroid plexus volume. This was evaluated in 50 of 135 patients with RRMS.

\section{Choroid Plexus Volume and Disease Characteristics in NMOSD}

In the NMOSD group, there was no association between the choroid plexus volume and disease duration, EDSS score, relapse in the year before the MRI, time to the last relapse, DMT category, DMT duration, T2w lesion number, or volume (data not shown). 
Figure 2 Choroid Plexus Volume in Multiple Sclerosis, Neuromyelitis Optica Spectrum Disorder, Migraine, and Healthy Individuals

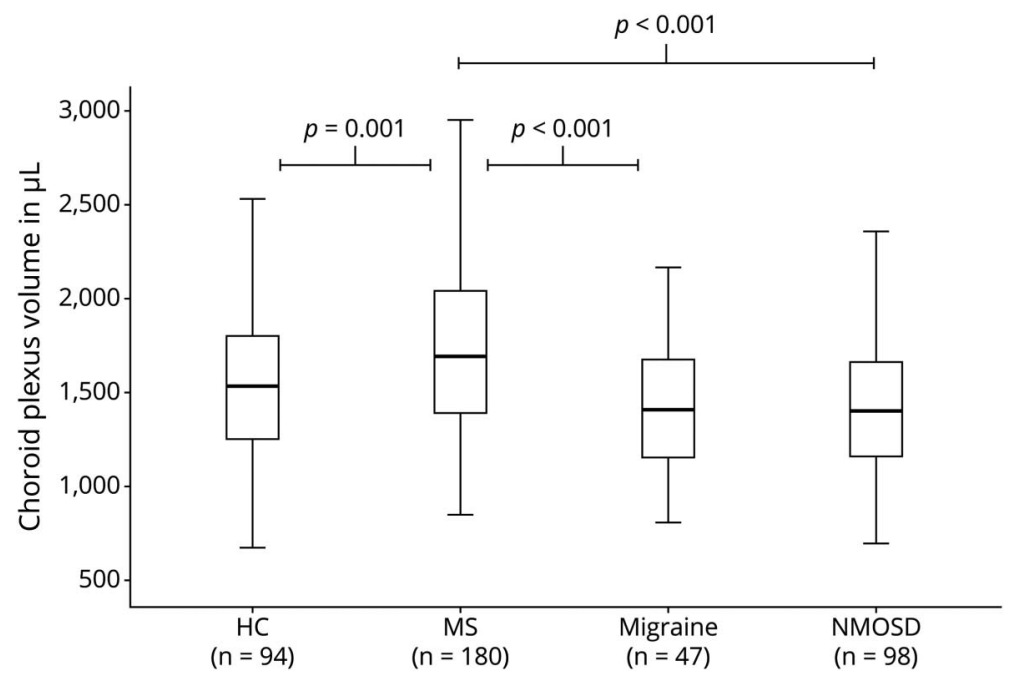

$p$ Values given in this figure derived from linear models adjusted for age, sex and total intracranial volume. $\mathrm{HC}=$ healthy controls; $\mathrm{MS}=$ multiple sclerosis; $\mathrm{n}=$ number; NMOSD = neuromyelitis optica spectrum disorder.

\section{Choroid Plexus Volume to Differentiate MS From NMOSD}

The choroid plexus volume was able to differentiate MS from NMOSD with an accuracy of 0.68 (area under the ROC curve 0.68; 95\% CI: 0.62-0.75; $p<0.001$; Figure 3); this was marginally lower compared with the number of T2w lesions to distinguish the 2 diseases (area under the ROC curve 0.70, 95\% CI: 0.63-0.77; $p<0.001$; Figure 3). $\mathrm{T} 2 \mathrm{w}$ lesion number and the choroid plexus volume were significantly higher in MS than NMOSD independent from each other.

To estimate the effect size of the choroid plexus volume to differentiate MS from NMOSD, we used a logistic regression model with disease group (MS vs NMOSD) as dependent variable and choroid plexus volume as independent parameter, adjusted for clinically meaningful parameters (eTable 3, links. lww.com/NXI/A701). The results indicated that a $100 \mu \mathrm{L}$

Table 3 Association Between Choroid Plexus Volume and Disease Characteristics in MS (Linear Model)

\begin{tabular}{|c|c|c|c|c|}
\hline \multicolumn{5}{|c|}{ Group: MS $(n=180)$ dependent variable: choroid plexus volume } \\
\hline & \multirow[b]{2}{*}{ Beta } & \multicolumn{2}{|l|}{$\underline{95 \% \mathrm{Cl}}$} & \multirow[b]{2}{*}{$p$ Value } \\
\hline & & Lower bound & Upper bound & \\
\hline Age (y) & 0.568 & 0.013 & 1.122 & 0.045 \\
\hline Sex & -122.612 & -272.658 & 27.434 & 0.108 \\
\hline Disease duration (mo) & 0.156 & -0.535 & 0.847 & 0.656 \\
\hline Relapse in the year before MRI (yes/no) & 25.110 & -143.402 & 193.623 & 0.769 \\
\hline MS disease course (RRMS; SPMS) & -176.561 & -388.299 & 35.177 & 0.101 \\
\hline EDSS score & 3.224 & -41.712 & 48.161 & 0.887 \\
\hline DMT (category) ${ }^{a}$ & 106.945 & -0.547 & 214.437 & 0.051 \\
\hline DMT duration (months) & 1.671 & -0.131 & 3.474 & 0.069 \\
\hline Total intracranial volume $/ \mu \mathrm{L}$ & 0.001 & 0.001 & 0.001 & $<0.001^{*}$ \\
\hline Number of T2w lesions & 4.431 & 0.777 & 8.085 & $0.018^{*}$ \\
\hline
\end{tabular}

Abbreviations: DMT = disease-modifying treatment; EDSS = Expanded Disability Status Scale; MS = multiple sclerosis; RRMS = relapsing-remitting multiple sclerosis; SPMS = secondary progressive multiple sclerosis; T2w = T2 weighted.

Significant associations are marked with an asterisk. In MS, the number of T2w lesions was associated with the choroid plexus volume independent of disease duration, clinical disease activity, disability status, and disease-modifying treatment.

a DMT categories: low efficacy = interferon-beta or glatiramer acetate; medium efficacy: dimethyl fumarate, fingolimod, or teriflunomide; high efficacy: natalizumab, rituximab, ocrelizumab, or stem cell therapy. 
Figure 3 Receiver Operating Characteristic Curves to Differentiate Multiple Sclerosis $(n=180)$ From Neuromyelitis Optica Spectrum Disorder $(n=98)$

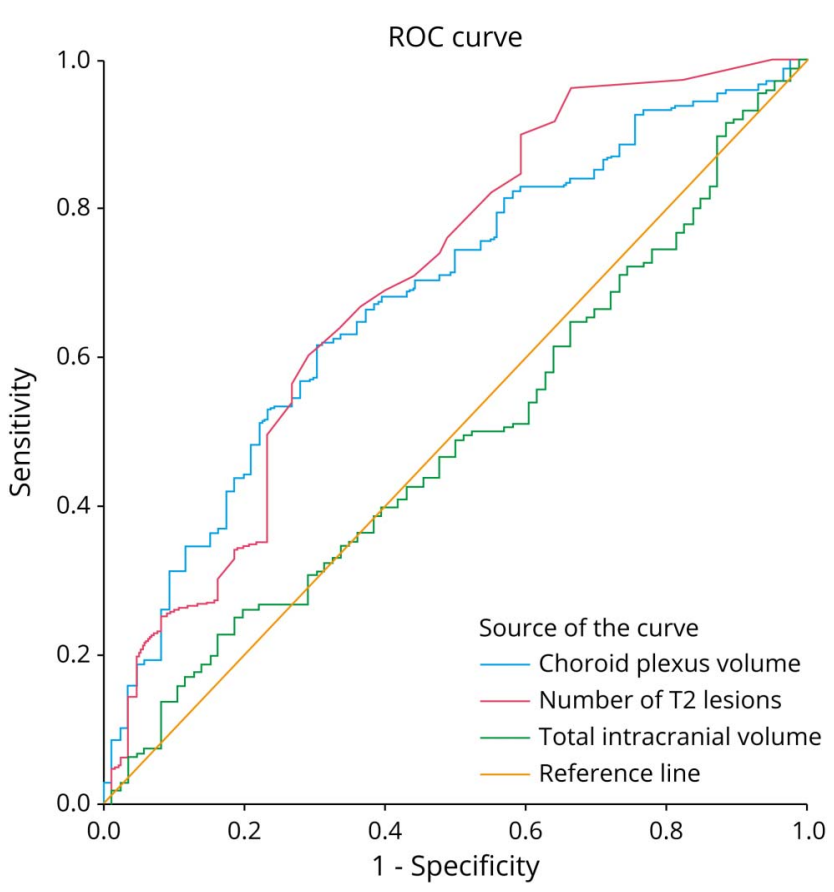

The accuracy to differentiate MS from NMOSD using the choroid plexus volume is comparable to the T2w lesion burden. Please note that the choroid plexus volume is associated with the diagnosis of MS (vs. NMOSD) independent of the number of T2w lesions (eTable 2, links.Iww.com/NXI/A701). a. Under the nonparametric assumption

b. Null hypothesis: true area $=0.5$

larger choroid plexus increased the risk of having MS instead of NMOSD statistically by $26 \%(\operatorname{Exp}(B): 1.259 ; 95 \%$ CI: 1.130-1.404) independently of sex, disease duration, relapse in the year before the MRI, EDSS score, and TIV but also independently of the number of $\mathrm{T} 2 \mathrm{w}$ lesions (eTable 3 ).

\section{Sensitivity Analyses}

In 10 patients with MS and 10 patients with NMOSD, we additionally segmented the infratentorial parts of the choroid plexus manually and blinded to the clinical data (eFigure 1, links.lww.com/NXI/A701). Including these infratentorial parts of the choroid plexus into the model did not alter the overall results. The median choroid plexus volume was larger in MS than NMOSD, adjusted for age, sex, and TIV (beta 196; 95\% CI: $29-362, p=0.024)$. The median choroid plexus volume was $16.7 \%$ higher in MS than NMOSD (2025 $\mu \mathrm{L}$, IQR 503 vs $1735 \mu \mathrm{L}$, IQR $545 \mu \mathrm{L})$.

Moreover, including the scanner type, the study center, or the lateral ventricle volume as covariates to the models did not alter the overall results (all $p>0.05$, estimates not shown). When analyzing the $25 \%$ of patients with MS with the lowest number of T2w lesions $(n=46)$, the choroid plexus volume was still larger in MS than in NMOSD, adjusted for age, sex, and total intracranial volume (beta $64 ; 95 \%$ CI: $20-108 ; p=0.005$ ).

\section{Discussion}

This study found larger choroid plexus in patients with MS than NMOSD, migraine, or HCs (adjusted for age, sex, and TIV), whereas there was no difference between patients with NMOSD, migraine, and HCs. These results suggest an involvement of the choroid plexus in MS-related inflammation and no or clearly less choroid plexus involvement in NMOSD.

Our results are in line with other MRI studies ${ }^{9}$ but not all. ${ }^{15}$ The enlargement of the choroid plexus in MS vs HCs was more pronounced in a previous study ${ }^{9}$ than in our study. In that study ${ }^{9}$, the choroid plexus volume adjusted for TIV was 35\% larger in MS than in HCs compared with $21 \%$ in our study. ${ }^{9}$ This might be due to the inclusion of less active MS patients in our study. In our MS group, $33 \%$ of the patients with RRMS had a relapse in the 2 years before the MRI, and only 2 of 180 patients with MS had gadolinium enhancement in contrast to $80 \%$ and $32 \%$, respectively, in the aforementioned study. ${ }^{9}$ These differences in the disease characteristics of the patients included are important as it has been shown that the choroid plexus volume is associated with both clinical and MRI disease activity in MS. ${ }^{9}$ The inclusion of more clinically and MRI stable patients with MS in our study might also explain why we have not found any difference in the choroid plexus volume between patients with and without a recent relapse. Only $15 \%$ of the patients in our study had a relapse in the 12 months before the MRI. In the entire MS group, we even found a tendency toward larger choroid plexus in patients with longer time since last relapse. However, further analysis elucidated that this association was driven by the higher $\mathrm{T} 2 \mathrm{w}$ lesion burden in patients with longer time since last relapse because when we adjusted for the $\mathrm{T} 2 \mathrm{w}$ lesion burden, the association between the time to last relapse and the choroid plexus volume lost statistical significance. This was also confirmed in a multivariable linear model with the choroid plexus volume as dependent variable and the number of $\mathrm{T} 2 \mathrm{w}$ lesions and relapses in the previous year as covariates (Table 3). Relapses in the previous year were not associated with the choroid plexus volume when the T2w lesion number was included into the model. In summary, our study built on the results of a previous work ${ }^{9}$ and found larger choroid plexus in MS vs HCs even in a less active MS patient population. Similar to the aforementioned study. ${ }^{9}$ our study could not find an association between disease duration and the choroid plexus volume in MS.

In contrast, the association between the choroid plexus volume and $\mathrm{T} 2 \mathrm{w}$ lesion burden in our study was strong and remained stable when the linear model was adjusted for clinically meaningful covariates (Table 3). Similar results were found in a previous work ${ }^{9}$ in which the choroid plexus enlargement correlated with the number of white matter lesions. As the $\mathrm{T} 2 \mathrm{w}$ lesion burden is an objective parameter of focal inflammation, our result suggests that the larger choroid plexus in MS compared with HCs might be related directly to MS inflammation. Our study built on these data and found that this association does not seem to be driven by the lesion location, at least not near to the ventricle wall. We measured in a subgroup of patients with RRMS the distance between the T2w lesions and the lateral 
ventricle wall and could not find any association to the choroid plexus volume. Although the T2w lesion burden showed a strong association with the choroid plexus volume, the number of T2w lesion lesions could not entirely explain the variance in the choroid plexus size in MS. There are 2 arguments in our study supporting this hypothesis: (1) in the subgroup of patients with RRMS with a low MRI disease burden, the choroid plexus was still larger in MS than HCs (see Sensitivity Analyses), and (2) in a linear model with the choroid plexus volume as dependent variable, the disease group (MS vs NMOSD) was associated with the choroid plexus volume independent of the T2w lesion burden (eTable 2, links.lww.com/NXI/A701).

This work is not the first study that has investigated the choroid plexus size in MS vs NMOSD. A recent work ${ }^{15}$ found $9-11 \%$ larger choroid plexus in MS vs NMOSD compared with $20 \%$ in our study. In contrast to our study, the differences between MS and NMOSD in that study ${ }^{15}$ did not reach statistical significance. At first glance, this might be surprising as the aforementioned study ${ }^{15}$ included more active patients than our study. The median time between the last relapse and MRI was 11 days in NMOSD and 16 days in MS in that study ${ }^{15}$ compared with 3.3 years and 4.5 years, respectively, in our study. Moreover, the disease duration was 2-3x shorter compared with our study. On the other hand, that study ${ }^{15}$ also did not find any difference in the choroid plexus volume between MS and HCs, either. This suggests that the methods used in that study ${ }^{15}$ to measure the choroid plexus size might have been too inaccurate to find a significant difference between MS and NMOSD. A recent study that segmented the choroid plexus manually on 3D T1w sequences even found differences in the choroid plexus volume between a presymptomatic stage of MS (radiologically isolared syndrome) and HCs. ${ }^{10}$

A reason for the discrepancy between our study and the aforementioned study ${ }^{15}$ could be the relatively higher sample size in our study. Low sample sizes are prone to the type II errors, which is the risk of concluding that there is no significant difference between the groups when in fact such a difference exists. The aforementioned study ${ }^{15}$ included 51 patients with MS, 32 patients with NMOSD, and $26 \mathrm{HCs}$, whereas our study included more than 2-3x more study participants (180 patients with MS, 98 patients with NMOSD, and $94 \mathrm{HCs}$ ). Moreover, we segmented the choroid plexus on high-resolution 3D images (slice thickness $1 \mathrm{~mm}$ ). They ${ }^{15}$ used linear measures on axial and coronal planes with a slice thickness of $5 \mathrm{~mm}$. On the other hand, and this is certainly an advantage, they ${ }^{15}$ also measured the choroid plexus of the fourth ventricle but analyzed these results separately from the choroid plexus in the lateral ventricles. In contrast, we only included the infratentorial parts of the choroid plexus in a sensitivity analysis in a subgroup of our patients and found results compared to our main analysis. A further advantage of our study is that we included study subjects from 4 different MS centers and different regions of the world in contrast to the recent single-center work ${ }^{15}$ which might make our results more generalizable. We further have not included only healthy individuals as a control group but also patients with migraine as an example of a nonautoimmune inflammatory CNS disease, which might strengthen our results.
The larger choroid plexus volume in MS compared to NMOSD is not only important to better understand the pathophysiologic differences between these conditions. Our results might also have clinical implications in the future. The differential diagnosis between MS and NMOSD is clinically important and often challenging, ${ }^{18,29}$ in particular, if characteristic MRI findings such as longitudinal extensive transverse myelitis, Dawson fingers, or other imaging hallmarks are missing, and if the aquaporin-4 antibody status is negative. Our ROC curve analysis suggested that the choroid plexus volume might be helpful as a MRI biomarker in addition to the brain T2w lesion number to discriminate MS from NMOSD. However, further prospective studies are needed to prove this hypothesis.

Our study is not without limitations. We excluded the choroid plexus of the fourth ventricle and the subarachnoid space (Bochdalek flower baskets) as these parts of the choroid plexus were difficult to delineate. The excluded part of the choroid plexus represents about $35 \%$ of the entire choroid plexus. ${ }^{15}$ However, in a sensitivity analysis, we were able to reliably segment the infratentorial parts of the choroid plexus in 20 patients by consensus between 3 raters. Including these infratentorial parts into the analysis did not alter the overall results of the study.

Head size is an important factor affecting the choroid plexus volume. To mitigate this effect, we adjusted all statistical models similar to other studies ${ }^{9}$ for TIV and in a sensitivity analysis also for the lateral ventricle volumes, with similar results compared with the main analysis. However, residual effects might still have affected our results.

Patients were scanned on different scanners and therefore had slightly different MRI acquisition parameters, which might have influenced our results. However, we made sure that the magnetic field strength and the image resolution were constant across all scanners and scan protocols. Moreover, including the scanner type in a sensitivity analysis as a covariate into the statistical model did not alter the overall results. However, again, residual effects might have affected our results.

The choroid plexus is larger in MS than in NMOSD. The involvement of the choroid plexus in MS (in contrast to NMOSD) provides clues to better understand the respective pathogenesis. Further prospective studies are warranted to investigate whether the choroid plexus volume is useful to differentiate MS from NMOSD in clinical practice.

\section{Acknowledgment}

The authors thank Dr Nicholas Sanderson for the review of the paper.

\section{Study Funding}

No targeted funding reported.

\section{Disclosure}

J. Müller received ad personam funding from the Swiss Academy of Medical Science (Schweizer Akademie der 
Medizinischen Wissenschaften, SAMW). T. Sinnecker is parttime employee of the Medical Image Analysis Center Basel. MJ. Wendebourg and R. Schlaeger report no competing interests. J. Kuhle received speaker fees, research support, travel support, and/or served on advisory boards by ECTRIMS, Swiss MS Society, Swiss National Research Foundation [320030_160221], University of Basel, Bayer, Biogen, Genzyme, Merck, Novartis, Protagen AG, Roche, and Teva. Sabine Schaedelin and Pascal Benkert have nothing to disclose. T. Derfuss received speaker fees, travel support, and/or served on advisory boards or steering committees of Novartis Pharma, Merck, Biogen, GeNeuro, Mitsubishi Pharma, MedDay, Roche, Celgene, Alexion, Actelion, and Genzyme; he received research support from Biogen, Novartis, Roche, Alexion, the Swiss National Research Foundation, University of Basel, and the Swiss MS Society. P. Cattin, C. Jud, F. Spiess, M. Amann, T. Lincke, M. Barakovic, A. Cagol, Ch. Tsagkas, and K.Parmar report no competing interest. AK. Pröbstel received speaker fees, travel support, and/or served on advisory boards of Novartis Pharma and Roche; she received research support from Biogen, the Swiss National Research Foundation, the National Multiple Sclerosis Society, the European Research Council, University of Basel, the Propatient Foundation, and the Goldschmidt-Jacobson Foundation. S. Reimann reports no competing interest. S. Asseyer received travel grant from Celgene and speaker's honorary from Roche and Bayer. A. Duchow received a speakers's honorary from Roche. A. Brandt reports no competing interest. K. Ruprecht received research support from Novartis Pharma, Merck Serono, Federal Ministry of Education and Research (Bundesministerium für Bildung und Forschung), European Union (821283-2), Stiftung Charité (BIH Clinical Fellow Program), and Arthur Arnstein Foundation and received speaker honoraria from Bayer and travel grants from the Guthy-Jackson Charitable Foundation. N. Hadjikhani and S. Fukumoto report no competing interests. M. Watanabe received speaker honoraria from Novartis Pharma and a grant from JSPS KAKENHI (Grant No. 19K07995) and GlaxoSmithKline. K. Masaki reports no competing interests. T. Matsushita received speech honoraria payments from Biogen Japan, Chugai Pharmaceutical, Alexion Pharmaceuticals, Novartis Pharma, and Takeda Pharmaceutical Company. N. Isobe received grant support from Mitsubishi Tanabe Pharma, Osoegawa Neurology Clinic, Bayer Yakuhin Ltd., and Japan Blood Products Organization and speaker honoraria from Novartis Pharma, Biogen Japan, Alexion, Mitsubishi Tanabe Pharma, Chugai Pharmaceutical Co. Ltd., Teijin Pharma, and Eisai Co., Ltd. J. Kira received research funds from Dainippon Sumitomo Pharma, Daiichi Sankyo, Mitsubishi Tanabe Pharma, and Kyowa Kensetsukougyo and consultancy fees, speaking fees, and/or honoraria from Novartis Pharma, Mitsubishi Tanabe Pharma, CSL Behring, Biogen Japan, Teijin Health Care, the Takeda Pharmaceutical Company, Kyowa Kirin, Ono Pharmaceutical Co. Ltd., Alexion Pharmaceuticals Inc., Tsumura, Ricoh, EMC, and Eisai. L. Kappos' institution (University Hospital Basel) received and used exclusively for research support: steering committee, advisory board, and consultancy fees (Actelion, Bayer HealthCare, Biogen, BMS, Genzyme, Janssen, Merck, Novartis, Roche, Sanofi, Santhera, and TG Therapeutics); speaker fees (Bayer HealthCare, Biogen, Merck, Novartis, Roche, and Sanofi); support of educational activities (Allergan, Bayer HealthCare, Biogen, CSL Behring, Desitin, Genzyme, Merck, Novartis, Roche, Pfizer, Sanofi, Shire, and Teva); license fees for Neurostatus products; and grants (Bayer HealthCare, Biogen, European Union, InnoSwiss, Merck, Novartis, Roche, Swiss MS Society, and Swiss National Research Foundation). M. Amann reports no competing interests. J. Wuerfel is employee of MIAC AG; he served for advisory boards for Biogen, Idorsia, Novartis, Roche, and Sanofi; he is or was supported by the EU (Horizon2020), the German Ministeries for Economy and Science and Education. C. Granziera's institution, the University Hospital Basel (USB), has received the following fees, which were used exclusively for research support: (1) advisory board and consultancy fees from Actelion, Novartis, Genzyme-Sanofi, and F. Hoffmann-La Roche Ltd; (2) speaker fees from Biogen and Genzyme-Sanofi; and (3) collaborative research funds by F. Hoffmann-La Roche Ltd. F. Paul reports no competing interests. Ö. Yaldizli received grants from ECTRIMS/MAGNIMS, University of Basel, Pro Patient Stiftung, University Hospital Basel, Free Academic Society Basel, and the Swiss Multiple Sclerosis Society and advisory board fees from Roche, Sanofi Genzyme, Biogen, Almirall, and Novartis. Go to Neurology.org/NN for full disclosures.

\section{Publication History}

Received by Neurology: Neuroimmunology \& Neuroinflammation August 3, 2021. Accepted in final form January 18, 2022. Submitted and externally peer reviewed. The handling editor was Scott S. Zamvil, MD, PhD, FAAN.

\begin{tabular}{|c|c|c|}
\hline Name & Location & Contribution \\
\hline $\begin{array}{l}\text { Jannis Müller, } \\
\text { MD }\end{array}$ & $\begin{array}{l}\text { Neurology Clinic and } \\
\text { Policlinic, Departments of } \\
\text { Head, Spine and } \\
\text { Neuromedicine, MS Center } \\
\text { and Research Center for } \\
\text { Clinical Neuroimmunology } \\
\text { and Neuroscience Basel } \\
\text { (RC2NB), Clinical Research } \\
\text { and Biomedical Engineering, } \\
\text { University Hospital Basel and } \\
\text { University of Basel; } \\
\text { Translational Imaging in } \\
\text { Neurology (ThINk) Basel, } \\
\text { Department of Biomedical } \\
\text { Engineering, University } \\
\text { Hospital Basel and University } \\
\text { of Basel, Switzerland }\end{array}$ & $\begin{array}{l}\text { Drafting/revision of the } \\
\text { manuscript for content, } \\
\text { including medical writing } \\
\text { for content; major role in } \\
\text { the acquisition of data; } \\
\text { study concept or design; } \\
\text { and analysis or } \\
\text { interpretation of data }\end{array}$ \\
\hline $\begin{array}{l}\text { Tim } \\
\text { Sinnecker, } \\
\text { MD }\end{array}$ & $\begin{array}{l}\text { Neurology Clinic and } \\
\text { Policlinic, Departments of } \\
\text { Head, Spine and } \\
\text { Neuromedicine, MS Center } \\
\text { and Research Center for } \\
\text { Clinical Neuroimmunology } \\
\text { and Neuroscience Basel } \\
\text { (RC2NB), Clinical Research } \\
\text { and Biomedical Engineering, } \\
\text { University Hospital Basel and } \\
\text { University of Basel, Switzerland }\end{array}$ & $\begin{array}{l}\text { Drafting/revision of the } \\
\text { manuscript for content, } \\
\text { including medical writing } \\
\text { for content, and analysis } \\
\text { or interpretation of data }\end{array}$ \\
\hline
\end{tabular}


Appendix (continued)

\begin{tabular}{|c|c|c|}
\hline Name & Location & Contribution \\
\hline $\begin{array}{l}\text { Maria Janina } \\
\text { Wendebourg, } \\
\text { MD }\end{array}$ & $\begin{array}{l}\text { Neurology Clinic and } \\
\text { Policlinic, Departments of } \\
\text { Head, Spine and } \\
\text { Neuromedicine, MS Center } \\
\text { and Research Center for } \\
\text { Clinical Neuroimmunology } \\
\text { and Neuroscience Basel } \\
\text { (RC2NB), Clinical Research } \\
\text { and Biomedical Engineering, } \\
\text { University Hospital Basel and } \\
\text { University of Basel, Switzerland }\end{array}$ & $\begin{array}{l}\text { Drafting/revision of the } \\
\text { manuscript for content, } \\
\text { including medical writing } \\
\text { for content, and major } \\
\text { role in the acquisition of } \\
\text { data }\end{array}$ \\
\hline $\begin{array}{l}\text { Regina } \\
\text { Schläger, MD }\end{array}$ & $\begin{array}{l}\text { Neurology Clinic and } \\
\text { Policlinic, Departments of } \\
\text { Head, Spine and } \\
\text { Neuromedicine, MS Center } \\
\text { and Research Center for } \\
\text { Clinical Neuroimmunology } \\
\text { and Neuroscience Basel } \\
\text { (RC2NB), Clinical Research } \\
\text { and Biomedical Engineering, } \\
\text { University Hospital Basel and } \\
\text { University of Basel, Switzerland }\end{array}$ & $\begin{array}{l}\text { Drafting/revision of the } \\
\text { manuscript for content, } \\
\text { including medical writing } \\
\text { for content, and major } \\
\text { role in the acquisition of } \\
\text { data }\end{array}$ \\
\hline $\begin{array}{l}\text { Jens Kuhle, } \\
\text { MD, PhD }\end{array}$ & $\begin{array}{l}\text { Neurology Clinic and } \\
\text { Policlinic, Departments of } \\
\text { Head, Spine and } \\
\text { Neuromedicine, MS Center } \\
\text { and Research Center for } \\
\text { Clinical Neuroimmunology } \\
\text { and Neuroscience Basel } \\
\text { (RC2NB), Clinical Research } \\
\text { and Biomedical Engineering, } \\
\text { University Hospital Basel and } \\
\text { University of Basel, Switzerland }\end{array}$ & $\begin{array}{l}\text { Drafting/revision of the } \\
\text { manuscript for content, } \\
\text { including medical writing } \\
\text { for content; major role in } \\
\text { the acquisition of data; } \\
\text { and analysis or } \\
\text { interpretation of data }\end{array}$ \\
\hline $\begin{array}{l}\text { Sabine } \\
\text { Schädelin, } \\
\text { MSc }\end{array}$ & $\begin{array}{l}\text { Neurology Clinic and Policlinic, } \\
\text { Departments of Head, Spine } \\
\text { and Neuromedicine, MS } \\
\text { Center and Research Center } \\
\text { for Clinical Neuroimmunology } \\
\text { and Neuroscience Basel } \\
\text { (RC2NB), Clinical Research and } \\
\text { Biomedical Engineering, } \\
\text { University Hospital Basel and } \\
\text { University of Basel; } \\
\text { Translational Imaging in } \\
\text { Neurology (ThINk) Basel, } \\
\text { Department of Biomedical } \\
\text { Engineering, University } \\
\text { Hospital Basel and University } \\
\text { of Basel, Switzerland }\end{array}$ & $\begin{array}{l}\text { Drafting/revision of the } \\
\text { manuscript for content, } \\
\text { including medical writing } \\
\text { for content, and analysis } \\
\text { or interpretation of data }\end{array}$ \\
\hline $\begin{array}{l}\text { Pascal } \\
\text { Benkert, PhD }\end{array}$ & $\begin{array}{l}\text { Neurology Clinic and } \\
\text { Policlinic, Departments of } \\
\text { Head, Spine and } \\
\text { Neuromedicine, MS Center } \\
\text { and Research Center for } \\
\text { Clinical Neuroimmunology } \\
\text { and Neuroscience Basel } \\
\text { (RC2NB), Clinical Research } \\
\text { and Biomedical Engineering, } \\
\text { University Hospital Basel and } \\
\text { University of Basel, Switzerland }\end{array}$ & $\begin{array}{l}\text { Drafting/revision of the } \\
\text { manuscript for content, } \\
\text { including medical writing } \\
\text { for content, and analysis } \\
\text { or interpretation of data }\end{array}$ \\
\hline $\begin{array}{l}\text { Tobias } \\
\text { Derfuss, MD }\end{array}$ & $\begin{array}{l}\text { Neurology Clinic and } \\
\text { Policlinic, Departments of } \\
\text { Head, Spine and } \\
\text { Neuromedicine, MS Center } \\
\text { and Research Center for } \\
\text { Clinical Neuroimmunology } \\
\text { and Neuroscience Basel } \\
\text { (RC2NB), Clinical Research } \\
\text { and Biomedical Engineering, } \\
\text { University Hospital Basel and } \\
\text { University of Basel, Switzerland }\end{array}$ & $\begin{array}{l}\text { Drafting/revision of the } \\
\text { manuscript for content, } \\
\text { including medical writing } \\
\text { for content, and analysis } \\
\text { or interpretation of data }\end{array}$ \\
\hline
\end{tabular}

Appendix (continued)

\begin{tabular}{|c|c|c|}
\hline Name & Location & Contribution \\
\hline $\begin{array}{l}\text { Philippe } \\
\text { Cattin, PhD }\end{array}$ & $\begin{array}{l}\text { Department of Biomedical } \\
\text { Engineering, University of } \\
\text { Basel, Allschwil, Switzerland }\end{array}$ & $\begin{array}{l}\text { Drafting/revision of the } \\
\text { manuscript for content, } \\
\text { including medical writing } \\
\text { for content, and analysis } \\
\text { or interpretation of } \\
\text { data }\end{array}$ \\
\hline $\begin{array}{l}\text { Christoph } \\
\text { Jud, PhD }\end{array}$ & $\begin{array}{l}\text { Department of Biomedical } \\
\text { Engineering, University of } \\
\text { Basel, Allschwil, Switzerland }\end{array}$ & $\begin{array}{l}\text { Analysis or interpretation } \\
\text { of data }\end{array}$ \\
\hline $\begin{array}{l}\text { Florian } \\
\text { Spiess, MSc }\end{array}$ & $\begin{array}{l}\text { Department of Biomedical } \\
\text { Engineering, University of } \\
\text { Basel, Allschwil, Switzerland }\end{array}$ & $\begin{array}{l}\text { Drafting/revision of the } \\
\text { manuscript for content, } \\
\text { including medical writing } \\
\text { for content; major role in } \\
\text { the acquisition of data; } \\
\text { and analysis or } \\
\text { interpretation } \\
\text { of data }\end{array}$ \\
\hline
\end{tabular}

\begin{tabular}{|c|c|c|}
\hline $\begin{array}{l}\text { Michael } \\
\text { Amann, PhD }\end{array}$ & $\begin{array}{l}\text { Medical Imaging Analysis } \\
\text { Center AG }\end{array}$ & $\begin{array}{l}\text { Drafting/revision of the } \\
\text { manuscript for content, } \\
\text { including medical } \\
\text { writing for content; } \\
\text { major role in the } \\
\text { acquisition of data; } \\
\text { and analysis or } \\
\text { interpretation } \\
\text { of data }\end{array}$ \\
\hline
\end{tabular}

\begin{tabular}{lll}
\hline $\begin{array}{l}\text { Therese } \\
\text { Lincke, MD }\end{array}$ & $\begin{array}{l}\text { Section of Neuroradiology, } \\
\text { Clinic for Radiology \& Nuclear } \\
\text { Medicine, University Hospital } \\
\text { Basel and University of Basel, } \\
\text { Switzerland }\end{array}$ & $\begin{array}{l}\text { Drafting/revision of the } \\
\text { manuscript for content, } \\
\text { including medical } \\
\text { writing for content, and } \\
\text { analysis or interpretation } \\
\text { of data }\end{array}$ \\
\hline $\begin{array}{l}\text { Muhamed } \\
\text { Barakovic, } \\
\text { PhD }\end{array}$ & $\begin{array}{l}\text { Neurology Clinic and } \\
\text { Policlinic, Departments of }\end{array}$ & $\begin{array}{l}\text { Drafting/revision of the } \\
\text { manuscript for content, } \\
\text { Head, Spine and }\end{array}$ \\
$\begin{array}{l}\text { Neuromedicine, MS Center } \\
\text { and Research Center for } \\
\text { Clinical Neuroimmunology medical writing } \\
\text { and Neuroscience Basel }\end{array}$ & $\begin{array}{l}\text { for content; major role in } \\
\text { the acquisition of data; } \\
\text { and analysis or } \\
\text { interpretation of data }\end{array}$
\end{tabular}

(RC2NB), Clinical

Research and Biomedical

Engineering, University

Hospital Basel and

University of Basel;

Translational Imaging in

Neurology (ThINk)

Basel, Department of

Biomedical Engineering,

University Hospital

Basel and University

of Basel, Switzerland

\begin{tabular}{|c|c|c|}
\hline $\begin{array}{l}\text { Alessandro } \\
\text { Cagol, MD }\end{array}$ & $\begin{array}{l}\text { Neurology Clinic and } \\
\text { Policlinic, Departments of } \\
\text { Head, Spine and } \\
\text { Neuromedicine, MS Center } \\
\text { and Research Center for } \\
\text { Clinical Neuroimmunology } \\
\text { and Neuroscience Basel } \\
\text { (RC2NB), Clinical } \\
\text { Research and Biomedical } \\
\text { Engineering, University } \\
\text { Hospital Basel and } \\
\text { University of Basel; } \\
\text { Translational Imaging in } \\
\text { Neurology (ThINk) Basel, } \\
\text { Department of Biomedical } \\
\text { Engineering, University } \\
\text { Hospital Basel and } \\
\text { University of Basel, } \\
\text { Switzerland }\end{array}$ & $\begin{array}{l}\text { Drafting/revision of the } \\
\text { manuscript for content, } \\
\text { including medical writing } \\
\text { for content, and analysis } \\
\text { or interpretation of data }\end{array}$ \\
\hline
\end{tabular}


Appendix (continued)

\begin{tabular}{|c|c|c|}
\hline Name & Location & Contribution \\
\hline $\begin{array}{l}\text { Charidimos } \\
\text { Tsagkas, MD, } \\
\text { PhD }\end{array}$ & $\begin{array}{l}\text { Neurology Clinic and Policlinic, } \\
\text { Departments of Head, Spine } \\
\text { and Neuromedicine, MS } \\
\text { Center and Research Center } \\
\text { for Clinical Neuroimmunology } \\
\text { and Neuroscience Basel } \\
\text { (RC2NB), Clinical Research and } \\
\text { Biomedical Engineering, } \\
\text { University Hospital Basel and } \\
\text { University of Basel; } \\
\text { Translational Imaging in } \\
\text { Neurology (ThINk) Basel, } \\
\text { Department of Biomedical } \\
\text { Engineering, University } \\
\text { Hospital Basel and University } \\
\text { of Basel, Switzerland }\end{array}$ & $\begin{array}{l}\text { Drafting/revision of the } \\
\text { manuscript for content, } \\
\text { including medical writing } \\
\text { for content, and analysis } \\
\text { or interpretation of data }\end{array}$ \\
\hline
\end{tabular}

\begin{tabular}{ll}
\hline Katrin & Neurology Clinic and \\
Parmar, MD & Policlinic, Departments of \\
& Head, Spine and \\
& Neuromedicine, MS Center \\
& and Research Center for \\
& Clinical Neuroimmunology \\
& and Neuroscience Basel \\
& (RC2NB), Clinical Research \\
& and Biomedical Engineering, \\
& University Hospital Basel and \\
& University of Basel; \\
& Translational Imaging in \\
& Neurology (ThINk) Basel, \\
& Department of Biomedical \\
& Engineering, University \\
& Hospital Basel and University \\
& of Basel, Switzerland; Reha \\
& Rheinfelden, Rheinfelden, \\
& Switzerland
\end{tabular}

Anne-Katrin Neurology Clinic and Pröbstel, MD, Policlinic, Departments of PhD Head, Spine and

Neuromedicine, MS Center and Research Center for Clinical Neuroimmunology and Neuroscience Basel (RC2NB), Clinical Research and Biomedical Engineering, University Hospital Basel and University of Basel, Switzerland

\begin{tabular}{ll}
\hline Sophia & Neurology Clinic and \\
Reimann & Policlinic, Departments of \\
& Head, Spine and \\
& Neuromedicine, MS Center \\
& and Research Center for \\
& Clinical Neuroimmunology \\
& and Neuroscience Basel \\
& (RC2NB), Clinical Research \\
& and Biomedical Engineering, \\
& University Hospital Basel and \\
& University of Basel, Switzerland
\end{tabular}

\begin{tabular}{|c|c|c|}
\hline $\begin{array}{l}\text { Susanna } \\
\text { Asseyer, MD }\end{array}$ & $\begin{array}{l}\text { NeuroCure Clinical Research } \\
\text { Center and Experimental and } \\
\text { Clinical Research Center, Max } \\
\text { Delbrueck Center for } \\
\text { Molecular Medicine and } \\
\text { Charité-Universitätsmedizin } \\
\text { Berlin, Germany }\end{array}$ & $\begin{array}{l}\text { Drafting/revision of the } \\
\text { manuscript for content, } \\
\text { including medical writing } \\
\text { for content; major role in } \\
\text { the acquisition of data; } \\
\text { and analysis or } \\
\text { interpretation of data }\end{array}$ \\
\hline $\begin{array}{l}\text { Ankelien } \\
\text { Duchow, MD }\end{array}$ & $\begin{array}{l}\text { NeuroCure Clinical Research } \\
\text { Center and Experimental and } \\
\text { Clinical Research Center, Max } \\
\text { Delbrueck Center for } \\
\text { Molecular Medicine and } \\
\text { Charité-Universitätsmedizin } \\
\text { Berlin, Germany }\end{array}$ & $\begin{array}{l}\text { Drafting/revision of the } \\
\text { manuscript for content, } \\
\text { including medical writing } \\
\text { for content; major role in } \\
\text { the acquisition of data; } \\
\text { and analysis or } \\
\text { interpretation of data }\end{array}$ \\
\hline
\end{tabular}

Drafting/revision of the manuscript for content, including medical writing for content, and major role in the acquisition of data

Drafting/revision of the manuscript for content, including medical writing for content, and analysis or interpretation of data
Appendix (continued)

\begin{tabular}{|c|c|c|}
\hline Name & Location & Contribution \\
\hline $\begin{array}{l}\text { Alexander } \\
\text { Brandt, MD }\end{array}$ & $\begin{array}{l}\text { NeuroCure Clinical Research } \\
\text { Center and Experimental and } \\
\text { Clinical Research Center, Max } \\
\text { Delbrueck Center for } \\
\text { Molecular Medicine and } \\
\text { Charité-Universitätsmedizin } \\
\text { Berlin, Germany; Department } \\
\text { of Neurology, University of } \\
\text { California, Irvine }\end{array}$ & $\begin{array}{l}\text { Drafting/revision of the } \\
\text { manuscript for content, } \\
\text { including medical writing } \\
\text { for content, and major } \\
\text { role in the acquisition of } \\
\text { data }\end{array}$ \\
\hline
\end{tabular}

\begin{tabular}{lll}
\hline Klemens & Department of Neurology, & Drafting/revision of the \\
Ruprecht, MD & Charité-Universitätsmedizin & manuscript for content, \\
& Berlin, corporate member of & including medical writing \\
& $\begin{array}{l}\text { Freie Universität Berlin and } \\
\text { Humboldt-Universität zu }\end{array}$ & $\begin{array}{l}\text { for content, and major } \\
\text { role in the acquisition of } \\
\text { Berlin, Germany }\end{array}$ \\
\end{tabular}

\begin{tabular}{ll}
\hline $\begin{array}{l}\text { Nouchine } \\
\text { Hadjikhani, }\end{array}$ & Martinos Center for Biomedical \\
MD, PhD & General Hospital and Harvard \\
& Medical School, Boston; Gillberg \\
& Neuropsychiatry Center, \\
& Sahlgrenska Academy, \\
& University of Gothenburg, \\
& Sweden
\end{tabular}

\begin{tabular}{ll}
\hline Shoko & Department of Neurology, \\
Fukumoto, & Neurological Institute, \\
MD & Graduate School of Medical \\
& Sciences, Kyushu University, \\
& Fukuoka, Japan
\end{tabular}

Drafting/revision of the manuscript for content, including medical writing for content, and major role in the acquisition of data

\begin{tabular}{lll}
\hline Mitsuru & Department of Neurology, & $\begin{array}{l}\text { Drafting/revision of the } \\
\text { manuscript for content, }\end{array}$ \\
Watanabe, & Neurological Institute, & $\begin{array}{l}\text { maduate School of Medical } \\
\text { including medical writing }\end{array}$ \\
MD, PhD & $\begin{array}{l}\text { Graduater } \\
\text { Sciences, Kyushu University, }\end{array}$ & $\begin{array}{l}\text { for content, and major } \\
\text { role in the acquisition of } \\
\text { data }\end{array}$ \\
& Fukuoka, Japan & ata
\end{tabular}

Katsuhisa Department of Neurology,

Masaki, MD Neurological Institute,

Drafting/revision of the manuscript for content, including medical writing for content, and major role in the acquisition of data

Sciences, Kyushu University, Fukuoka, Japan

\begin{tabular}{ll}
\hline Takuya & Department of Neurology, \\
Matsushita, & Neurological Institute, \\
MD & Graduate School of Medical \\
& Sciences, Kyushu University, \\
& Fukuoka, Japan
\end{tabular}

Drafting/revision of the manuscript for content, including medical writing for content, and major role in the acquisition of data

Noriko Isobe, Department of Neurology,

MD, PhD Neurological Institute, Graduate School of Medical Sciences, Kyushu University, Fukuoka, Japan

Drafting/revision of the manuscript for content, including medical writing for content, and major role in the acquisition of data

\begin{tabular}{|c|c|c|}
\hline $\begin{array}{l}\text { Jun-Ichi Kira, } \\
\text { MD, PhD }\end{array}$ & $\begin{array}{l}\text { Department of Neurology, } \\
\text { Neurological Institute, Graduate } \\
\text { School of Medical Sciences, } \\
\text { Kyushu University, Fukuoka, } \\
\text { Japan; Department of } \\
\text { Neurology, Brain and Nerve } \\
\text { Center, Fukuoka Central } \\
\text { Hospital, International University } \\
\text { of Health and Welfare, Fukuoka; } \\
\text { Translational Neuroscience } \\
\text { Center, Graduate School of } \\
\text { Medicine, and School of } \\
\text { Pharmacy at Fukuoka, } \\
\text { International University of Health } \\
\text { and Welfare, Okawa, Japan }\end{array}$ & $\begin{array}{l}\text { Drafting/revision of the } \\
\text { manuscript for content, } \\
\text { including medical writing } \\
\text { for content, and major } \\
\text { role in the acquisition of } \\
\text { data }\end{array}$ \\
\hline
\end{tabular}


Appendix (continued)

\begin{tabular}{|c|c|c|}
\hline Name & Location & Contribution \\
\hline $\begin{array}{l}\text { Ludwig } \\
\text { Kappos, MD }\end{array}$ & $\begin{array}{l}\text { Neurology Clinic and } \\
\text { Policlinic, Departments of } \\
\text { Head, Spine and } \\
\text { Neuromedicine, MS Center } \\
\text { and Research Center for } \\
\text { Clinical Neuroimmunology } \\
\text { and Neuroscience Basel } \\
\text { (RC2NB), Clinical Research } \\
\text { and Biomedical Engineering, } \\
\text { University Hospital Basel and } \\
\text { University of Basel, Switzerland }\end{array}$ & $\begin{array}{l}\text { Drafting/revision of the } \\
\text { manuscript for content, } \\
\text { including medical writing } \\
\text { for content; major role in } \\
\text { the acquisition of data; } \\
\text { and study concept or } \\
\text { design }\end{array}$ \\
\hline
\end{tabular}

Engineering University of Basel manuscript for content Allschwil, Switzerland; Medical including medical writing Imaging Analysis Center AG; NeuroCure Clinical Research Center and Experimental and Clinical Research Center, Max Delbrueck Center for Molecular Medicine and Charité-Universitätsmedizin Berlin, Germany

\begin{tabular}{|c|c|c|}
\hline $\begin{array}{l}\text { Cristina } \\
\text { Granziera, } \\
\text { MD, PhD }\end{array}$ & $\begin{array}{l}\text { Neurology Clinic and Policlinic, } \\
\text { Departments of Head, Spine } \\
\text { and Neuromedicine, MS } \\
\text { Center and Research Center } \\
\text { for Clinical Neuroimmunology } \\
\text { and Neuroscience Basel } \\
\text { (RC2NB), Clinical Research and } \\
\text { Biomedical Engineering, } \\
\text { University Hospital Basel and } \\
\text { University of Basel; } \\
\text { Translational Imaging in } \\
\text { Neurology (ThINk) Basel, } \\
\text { Department of Biomedical } \\
\text { Engineering, University } \\
\text { Hospital Basel and University } \\
\text { of Basel, Switzerland; } \\
\text { Department of Biomedical } \\
\text { Engineering, University of } \\
\text { Basel, Allschwil, Switzerland }\end{array}$ & $\begin{array}{l}\text { Drafting/revision of the } \\
\text { manuscript for content, } \\
\text { including medical writing } \\
\text { for content; major role in } \\
\text { the acquisition of data; } \\
\text { study concept or design; } \\
\text { and analysis or } \\
\text { interpretation of data }\end{array}$ \\
\hline
\end{tabular}

Friedemann Paul, MD

\section{NeuroCure Clinical Research}

Center and Experimental and Clinical Research Center, Max Delbrueck Center for Molecular Medicine and Charité-Universitätsmedizin Berlin, Germany

Neurology Clinic and Policlinic,

\section{Özgür} Yaldizli, MD Departments of Head, Spine

\section{Drafting/revision of the} manuscript for content, including medical writing for content; major role in the acquisition of data; study concept or design; and analysis or interpretation of data

Neurology Clinic and Policlinic, Drafting/revision of the and Neuromedicine, MS Center and Research Center for Clinical Neuroimmunology and Neuroscience Basel (RC2NB), Clinical Research and Biomedical Engineering, University Hospital Basel and University of Basel;

Translational Imaging in Neurology (ThINk) Basel, Department of Biomedical Engineering, University Hospital Basel and University of Basel, Switzerland

\section{References}

1. Johanson CE, Conn PM. The CP-CSF nexus. In: Neuroscience in Medicine. Humana Press; 2003.

2. Benarroch EE. CP-CSF system: recent developments and clinical correlations. Neurology. 2016;86(3):286-296.

3. Schwartz $\mathrm{M}$, Baruch $\mathrm{K}$. The resolution of neuroinflammation in neurodegeneration: leukocyte recruitment via the choroid plexus. EMBO J. 2014;33(1):7-22.

4. Vercellino M, Votta B, Condello C, et al. Involvement of the choroid plexus in multiple sclerosis autoimmune inflammation: a neuropathological study. J Neuroimmunol. 2008;199(1-2):133-141.

5. Kaur C, Rathnasamy G, Ling EA. The choroid plexus in healthy and diseased brain. J Neuropathol Exp Neurol. 2016;75(3):198-213.

6. Lauer AN, Tenenbaum T, Schroten H, Schwerk C. The diverse cellular responses of the choroid plexus during infection of the central nervous system. Am J Physiol Cell Physiol. 2018;314(2):C152-C165.

7. Strominger I, Elyahu Y, Berner O, et al. The choroid plexus functions as a niche for T-cell stimulation within the central nervous system. Front Immunol. 2018;9: 1066 .

8. Wolburg H, Paulus W. Choroid plexus: biology and pathology. Acta Neuropathol. 2010;119(1):75-88.

9. Ricigliano VAG, Morena E, Colombi A, et al. Choroid plexus enlargement in inflammatory multiple sclerosis: 3.0-T MRI and translocator protein PET evaluation. Radiology. 2021;301(1):166-177.

10. Ricigliano VAG, Louapre C, Poirion E, et al. An imaging signature in choroid plexuses in pre-symptomatic multiple sclerosis. Poster Presented at Annual Meeting of the European Charcot Foundation; Nov 14-18, 2021; Baveno, Italy.

11. Lennon VA, Kryzer TJ, Pittock SJ, Verkman AS, Hinson SR. IgG marker of opticspinal multiple sclerosis binds to the aquaporin-4 water channel. J Exp Med. 2005; 202(4):473-477.

12. Parratt JD, Prineas JW. Neuromyelitis optica: a demyelinating disease characterized by acute destruction and regeneration of perivascular astrocytes. Mult Scler. 2010; 16(10):1156-1172.

13. Jarius S, Paul F, Weinshenker BG, Levy M, Kim HJ, Wildemann B. Neuromyelitis optica. Nat Rev Dis Primers. 2020;6(1):85.

14. Takeshita Y, Fujikawa S, Serizawa K, et al. New BBB model reveals that IL-6 blockade suppressed the BBB disorder, preventing onset of NMOSD. Neurol Neuroimmunol Neuroinflamm. 2021;8(6):e1076.

15. Kim H, Lim YM, Kim G, et al. Choroid plexus changes on magnetic resonance imaging in multiple sclerosis and neuromyelitis optica spectrum disorder. J Neurol Sci. 2020;415:116904.

16. Disanto G, Benkert P, Lorscheider J, et al. The Swiss multiple sclerosis cohort-study (SMSC): a prospective Swiss wide investigation of key phases in disease evolution and new treatment options. PLoS One. 2016;11(3):e0152347.

17. Polman $\mathrm{CH}$, Reingold SC, Banwell B, et al. Diagnostic criteria for multiple sclerosis: 2010 revisions to the McDonald criteria. Ann Neurol. 2011;69(2):292-302.

18. Wingerchuk DM, Banwell B, Bennett JL, et al. International consensus diagnostic criteria for neuromyelitis optica spectrum disorders. Neurology. 2015;85(2):177-189.

19. Headache classification committee of the International Headache Society (IHS) the International Classification of Headache disorders, 3rd edition. Cephalalgia. 2018; 38(1):1-211.

20. Lublin FD, Reingold SC, Cohen JA, et al. Defining the clinical course of multiple sclerosis: the 2013 revisions. Neurology. 2014;83(3):278-286.

21. Kurtzke JF. Rating neurologic impairment in multiple sclerosis: an expanded disability status scale (EDSS). Neurology. 1983;33(11):1444-1452.

22. Confavreux C, Vukusic S, Moreau T, Adeleine P. Relapses and progression of disability in multiple sclerosis. N Engl J Med. 2000;343(20):1430-1438.

23. Waters P, Reindl M, Saiz A, et al. Multicentre comparison of a diagnostic assay: aquaporin-4 antibodies in neuromyelitis optica. J Neurol Neurosurg Psychiatry. 2016; 87(9):1005-1015.

24. Reindl M, Schanda K, Woodhall M, et al. International multicenter examination of MOG antibody assays. Neurol Neuroimmunol Neuroinflamm. 2020; $7(2): \mathrm{e} 674$

25. Andermatt S, Pezold S, Amann M, Cattin PC. Multi-dimensional gated recurrent units for automated anatomical landmark localization. ArXiv. Preprint posted online August 9, 2017. arXiv:1708.02766. https://arxiv.org/pdf/1708.02766.pdf.

26. Jenkinson M, Beckmann CF, Behrens TE, Woolrich MW, Smith SM. FSL. NeuroImage. 2012;62:782-790.

27. Jarius S, Ruprecht K, Wildemann B, et al. Contrasting disease patterns in seropositive and seronegative neuromyelitis optica: a multicentre study of 175 patients. J Neuroinflammation. 2012;9:14.

28. Kruit MC, van Buchem MA, Hofman PA, et al. Migraine as a risk factor for subclinical brain lesions. JAMA. 2004;291(4):427-434.

29. Geraldes R, Ciccarelli O, Barkhof F, et al. The current role of MRI in differentiating multiple sclerosis from its imaging mimics. Nat Rev Neurol. 2018;14(4): 199-213. 


\title{
Neurology \\ Neuroimmunology \& Neuroinflammation
}

\author{
Choroid Plexus Volume in Multiple Sclerosis vs Neuromyelitis Optica Spectrum \\ Disorder: A Retrospective, Cross-sectional Analysis \\ Jannis Müller, Tim Sinnecker, Maria Janina Wendebourg, et al. \\ Neurol Neuroimmunol Neuroinflamm 2022;9; \\ DOI 10.1212/NXI.0000000000001147
}

This information is current as of February 25, 2022

\section{Updated Information \& \\ Services}

References

Citations

Subspecialty Collections

Permissions \& Licensing

Reprints including high resolution figures, can be found at: http://nn.neurology.org/content/9/3/e1147.full.html

This article cites 26 articles, 5 of which you can access for free at: http://nn.neurology.org/content/9/3/e1147.full.html\#\#ref-list-1

This article has been cited by 3 HighWire-hosted articles: http://nn.neurology.org/content/9/3/e1147.full.html\#\#otherarticles

This article, along with others on similar topics, appears in the following collection(s):

Devic's syndrome

http://nn.neurology.org//cgi/collection/devics_syndrome

MRI

http://nn.neurology.org//cgi/collection/mri

Multiple sclerosis

http://nn.neurology.org//cgi/collection/multiple_sclerosis

Information about reproducing this article in parts (figures,tables) or in its entirety can be found online at:

http://nn.neurology.org/misc/about.xhtml\#permissions

Information about ordering reprints can be found online:

http://nn.neurology.org/misc/addir.xhtml\#reprintsus

Neurol Neuroimmunol Neuroinflamm is an official journal of the American Academy of Neurology.

Published since April 2014, it is an open-access, online-only, continuous publication journal. Copyright

Copyright $\odot 2022$ The Author(s). Published by Wolters Kluwer Health, Inc. on behalf of the American

Academy of Neurology.. All rights reserved. Online ISSN: 2332-7812.

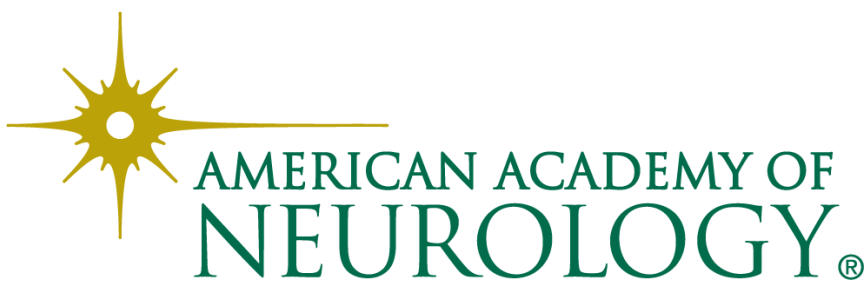

